Article

\title{
Farmers' Awareness in the Context of Climate Change: An Underutilized Way for Ensuring Sustainable Farmland Adaptation and Surface Water Quality
}

\author{
Ahmed Awad 1,2 $\mathbb{D}$, Wan Luo ${ }^{1, *}$, Nadhir Al-Ansari ${ }^{3, *(\mathbb{D}}$, Ahmed Elbeltagi ${ }^{4} \mathbb{D}_{\text {, Mustafa El-Rawy }}{ }^{5,6} \mathbb{D}$, \\ Hesham N. Farres ${ }^{7}$ and Mohamed EL-Sayed Gabr 8
}

1 College of Water Resources and Hydropower Engineering, Yangzhou University, Yangzhou 225009, China; eng_ahmed_awad@yahoo.com

2 Egyptian Ministry of Water Resources and Irrigation (MWRI), Giza 11925, Egypt

3 Civil, Environmental and Natural Resources Engineering, Lulea University of Technology, 97187 Lulea, Sweden

4 Agricultural Engineering Department, Faculty of Agriculture, Mansoura University, Mansoura 35516, Egypt ahmedelbeltagy81@mans.edu.eg

5 Civil Engineering Department, Faculty of Engineering, Minia University, Minia 61111, Egypt; mustafa.elrawy@mu.edu.eg

6 Civil Engineering Department, College of Engineering, Shaqra University, Dawadmi 11911, Saudi Arabia

7 Irrigation and Hydraulic Department, Faculty of Engineering, Ain Shams University, Cairo 11566, Egypt; hisham_nazme@eng.asu.edu.eg

8 Civil Engineering Department, High Institute for Engineering and Technology, New Damietta 34517, Egypt; mohamed.gabr@ndeti.edu.eg

updates

Citation: Awad, A.; Luo, W.; Al-Ansari, N.; Elbeltagi, A.; El-Rawy, M.; Farres, H.N.; Gabr, M.E.-S. Farmers' Awareness in the Context of Climate Change: An Underutilized Way for Ensuring Sustainable Farmland Adaptation and Surface Water Quality. Sustainability 2021, 13, 11802. https://doi.org/10.3390/ su132111802

Academic Editor: Piotr Prus

Received: 17 September 2021

Accepted: 20 October 2021

Published: 26 October 2021

Publisher's Note: MDPI stays neutral with regard to jurisdictional claims in published maps and institutional affiliations.

Copyright: (c) 2021 by the authors. Licensee MDPI, Basel, Switzerland. This article is an open access article distributed under the terms and conditions of the Creative Commons Attribution (CC BY) license (https:// creativecommons.org/licenses/by/ $4.0 /)$
* Correspondence: luowan@yzu.edu.cn (W.L.); nadhir.alansari@ltu.se (N.A.-A.)

Abstract: Simulations using the Crop Water and Irrigation Requirements model (CROPWAT), show that the projected climatic changes over the period from 2026 to 2050 in the Yanyun irrigation district, Yangzhou, China, will cause the paddy lands there to lose about $12.4 \%$ to $37.4 \%$, and $1.6 \%$ to $45.6 \%$, of their future seasonal rainwater in runoff under the Representative Concentration Pathways (RCP45 and RCP85), respectively. This may increase future irrigation requirements (IRs), alongside threatening the quality of adjacent water bodies. The CROPWAT simulations were re-run after increasing the Surface Storage Capacity (SSC) of the land by $50 \%$ and $100 \%$ of its baseline value. The results state that future rainwater runoff will be reduced by up to $76 \%$ and $100 \%$, and $53 \%$ and $100 \%$ when the SSC is increased by $50 \%$ and $100 \%$, under RCP45 and RCP85, respectively. This mitigates the future increase in IRs (e.g., under RCP45, up to about $11 \%$ and $16 \%$ of future IRs will be saved when increasing the SSC by $50 \%$ and $100 \%$, respectively), thus saving the adjacent water bodies from the contaminated runoff from these lands. Adjusting the SSC of farmlands is an easy physical approach that can be practiced by farmers, and therefore educating them on how to follow up the rainfall forecast and then adjust the level of their farmlands' boundaries according to these forecasts may help in the self-adaptation of vast areas of farmlands to climate change. These findings will help water users conserve agricultural water resources (by mitigating the future increase in IRs) alongside ensuring better quality for adjacent water bodies (by decreasing future runoff from these farmlands). Increasing farmers' awareness, an underutilized approach, is a potential tool for ensuring improved agricultural circumstances amid projected climate changes and preserving the available water resources.

Keywords: crop water requirements; irrigated agriculture; paddy fields; soil water balance; Surface Storage Capacity; water conservation

\section{Introduction}

Recently, in the year 2021, several disasters have occurred in many parts of the world, such as Germany, China, Greece and Turkey. These global disasters are potentially caused 
by climate change (Figure 1). The fear is that these climatic changes tend to be more severe and frequent than those predicted by specialists. The last IPCC report [1] was described as "a code red for humanity" because of the unprecedented and sometimes irreversible ways in which the global climate changes. Unfortunately, this report indicated that we will still overshoot the global warming limit of $1.5^{\circ} \mathrm{C}$ by 2030 , regardless of the relevant mitigation efforts and emissions reductions [1].

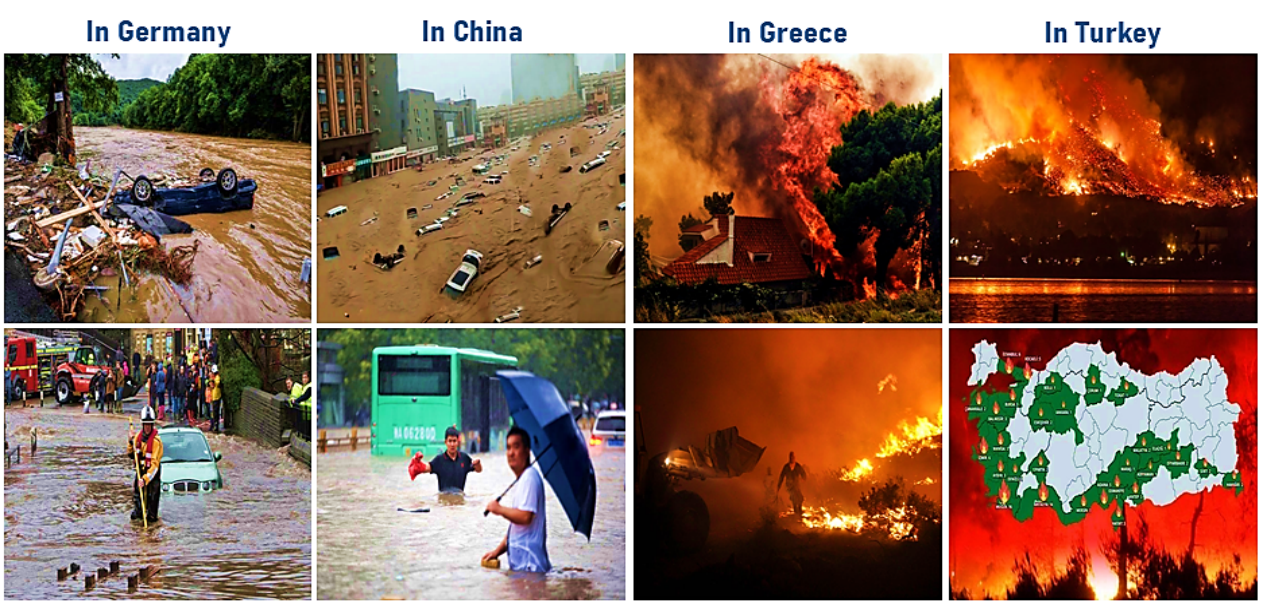

Figure 1. Examples of some global disasters that occurred in 2021 as a result of the severe climatic changes (modified after https: / / tinyurl.com/294ad77a, https: / / tinyurl.com/cvsp3vkw, https: / / tinyurl.com/2m2j5fcw, and https:/ / tinyurl.com/sy334kmm (accessed on 11 October 2021)).

Climate change affects many aspects of life. The agricultural sector is majorly affected while farmlands, in particular, are always exposed to more severe hazards due to such climatic changes. Many studies including those by Karimi et al. [2], Chandio et al. [3], and Malhi et al. [4] have reported the adverse impacts of climate change on agricultural practices and production. Generally, most of climate change's adverse impacts on farmlands are related to a "water story" in which climatic changes result in undesirable water distribution patterns in these lands, which in turn would adversely impact agricultural productivity, water resources, and the surrounding environment. An example of this is found on the lower reaches of the Yangtze River basin, where many studies, such as that by Su et al. [5], have projected a warmer climate and more frequent extreme storm events. These events tend to increase runoff, and Yin et al. [6] reported that these extreme storm runoffs caused by climate change increase globally at high rates even higher than what was suggested by Clausius Clapeyron scaling [7]. Such a phenomenon deprives the soil of large amount of rainwater, which is lost in the runoff. This represents a great challenge as regards making use of such water volumes in the light of limited water resources. In addition, such runoff carries many contaminants (e.g., nutrients, sediments, etc.) into adjacent water bodies [8,9], resulting in the severe deterioration of their quality [10,11] (Figure 2). Agricultural nonpoint source pollution has recently been identified as the leading threat to water quality in rivers and lakes, and many researchers have reported it to significantly contribute to water environment pollution in many countries [12-14]. 


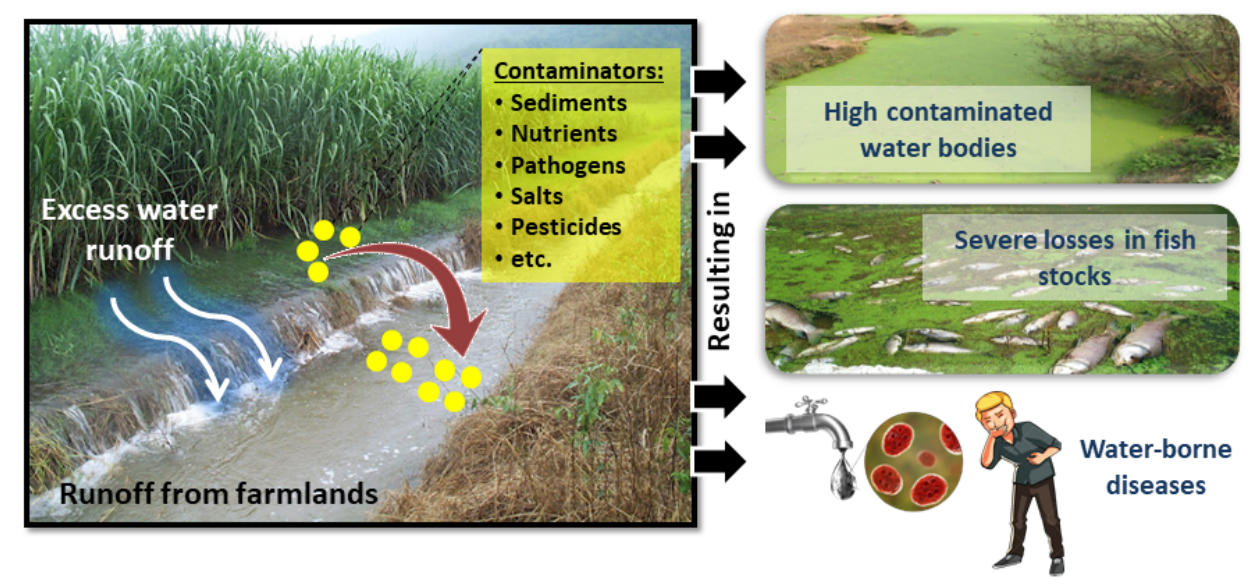

Figure 2. Runoff and nutrient transport from farmlands to adjacent water bodies.

Based on the above-mentioned, the adverse impacts of climate change on farmlands are not limited to the field scale, but rather extend to many other environmental resources. As such, mitigating such adverse impacts in farmlands will help to ensure high agricultural productivity and provide better conditions for the surrounding environment, thus easing the complexities of climate change adaptation policies.

Therefore, the present study aims to assess whether farmers in the lower reaches of the Yangtze River basin can self-manage their farmlands in a way that mitigates the projected adverse impacts of climate change (represented in the future higher runoff rates) on these lands to ensure better agricultural and environmental conditions. The adopted methodology will reduce the challenges and responsibilities of climate change adaptation authorities, as every farmer will be able to self-adapt their farm while also preventing it from exporting any risks to the surrounding environment. Despite the fact that farmers are the controller of agricultural activities and management practices in farmlands, there is a lack of studies that report on farmers' roles in climate change adaptation policies. Only very few studies, such as that by Arbuckle et al. [15], have considered and studied how farmers' awareness, concerns, and attitudes towards climate change affect the adaptation policies and outcomes. Therefore the present study aims to exploit the dominance and control of farmers over their farmlands to educate them on how to manage these lands and ensure the mitigation of climate change's adverse impacts, thus maximizing the underutilized role of farmers in climate change adaptation policies.

The methodology to help farmers achieve such adaptation is regarded as a tool by which the farmland water balance can be adjusted to is the level desired. In addition, such a tool should be easily and physically adjustable, with no complexities, in order to allow non-skilled farmers to achieve such adaptation.

As a rule, the land surface is the first receiver of water from precipitation or surface irrigation. Since the surface is not perfectly flat or smooth, irrigation or rainwater are collected in surface depressions, forming sinks and ponds. The maximum amount of water held per unit area is called the Surface Storage Capacity (SSC) [16]. Excess water accumulates in surface depressions under extreme precipitation events, where the rainfall exceeds the soil's infiltrability. When the ponding volume exceeds the SSC, water on the land surface starts to overflow from these puddles and runoff begins. So, SSC acts as the limit between the best utilization of irrigation or rainwater (when it is retained and infiltrates into the soil) and its loss (when it runs off). The higher the SSC, the better the utilization of water in farmlands due to the low runoff, and vice versa. Several studies have reported the efficiency of increasing SSC in farmlands, at large scales, as an approach that helps to retain water, thus mitigating runoff from these lands and conserving agricultural water [17-19]. 
Therefore, the present study aims to:

- Assess the role of SSC (as a simple physical approach that is easily managed and adjusted by farmers) in mitigating the projected climate change's adverse impacts on paddy lands' water balance at the lower reaches of the Yangtze River basin;

- Assess how such adaptation affects the future irrigation requirements in the study area.

The specific objectives of the study are to:

1. Project future (2026-2045) climate changes in the study area;

2. Estimate future rainwater losses and irrigation requirements corresponding to the projected climate changes by applying the CROPWAT model;

3. Re-run CROPWAT simulations under higher SSC conditions ( $50 \%$ and $100 \%$ higher than the baseline value) to assess the influence of SSC changes on future runoff losses and irrigation requirements.

The CROPWAT model was developed by the Food and Agriculture Organization (FAO) [20], and became a well-known tool that has been used by many researchers (e.g., Gabr et al. [21], Lalic et al. [22], Bhat et al. [23], etc.) to assess the potential impacts of changes in field conditions, weather patterns, agricultural practices, etc., on irrigation requirements and crop yield.

The findings of this study will make it easy to report the degree of efficiency of adjusting SSC, as a physical adaptation approach that farmers can use (due to its simplicity), in saving farmlands alongside the surrounding environment from the projected climate change's adverse impacts, thus indicating farmers' potential role in easing the challenges of climate change adaptation policies.

\section{Materials and Methods}

\subsection{Study Area}

The lower reaches of the Yangtze River basin are rich in paddy lands. A 1-hectare area was selected as the study area in these reaches, located at the Yangzhou Irrigation and Drainage Experimental Station, Yanyun irrigation district, Yangzhou City, China (Figure 3).
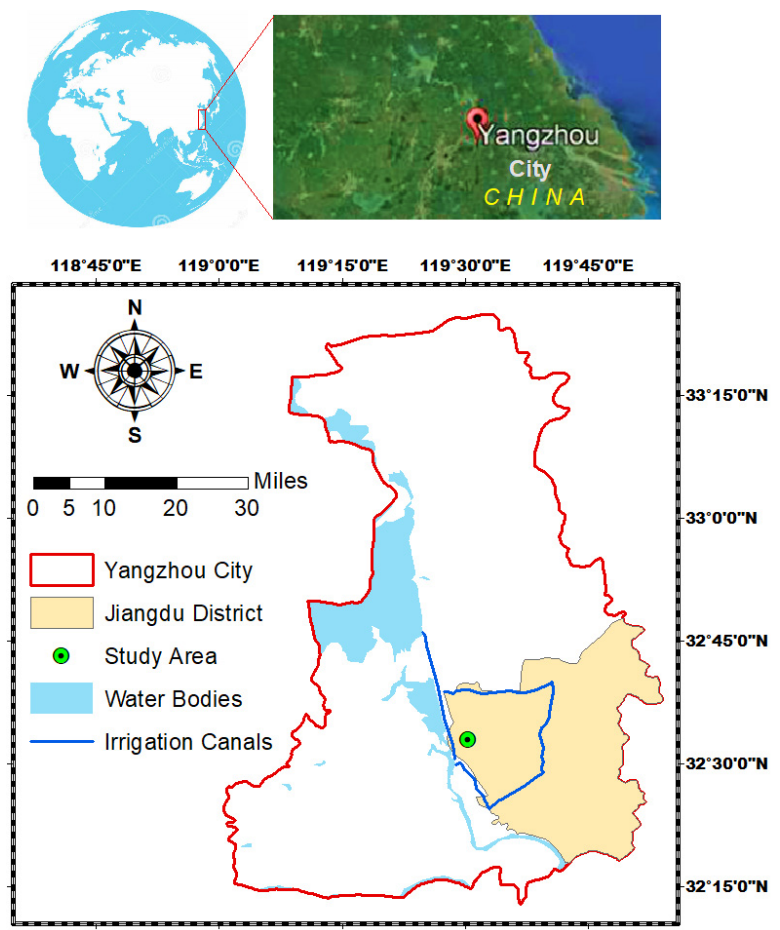

Figure 3. Study area; showing the location, the meteorological station, and the surrounding water bodies and canals. 
The area is characterized by a flat topography; the elevations here range from 5 to $8 \mathrm{~m}$ + MSL (mean sea level). The annual precipitation is about $1000 \mathrm{~mm}$ while the annual mean values of maximum and minimum temperatures are $21^{\circ} \mathrm{C}$ and $12.3^{\circ} \mathrm{C}$, respectively [24].

Rice grows in the study area from late June to early November. Despite the ample rainfall in the study area, irrigation is practiced during the rice-growing season to ensure the satisfaction of the high rice water requirements. Irrigation water is sourced from a nearby canal adjacent to the study area (Figure 3).

\subsection{CROPWAT Model}

The CROPWAT is an empirical process-based model developed by the Food and Agriculture Organization (FAO) to propose proper irrigation strategies that result in better crop management, and thus high agricultural productivity [20]. The model integrates several modules that are necessary to predict irrigation water requirements and their scheduling.

As shown in Figure 4, the model requires a set of data related to weather, crop, and field conditions in order to produce several outputs that help to better manage the agricultural process. Because of the weather input module, which comprises several weather parameters, CROPWAT has been reported and applied at a wide scale as a good tool that predicts the potential impacts of climate change on the future irrigation requirements of several crops, such as rice [25], soybean [26], peaches [27], potato [28], wheat and maize [29], etc. Therefore, the model was applied in the present study to assess future variations in irrigation requirements in the study area under the projected climate changes (2026-2045). The simulation period was divided into four periods: 2026 to 2030, 2031 to 2035, 2036 to 2040, and 2041 to 2045.

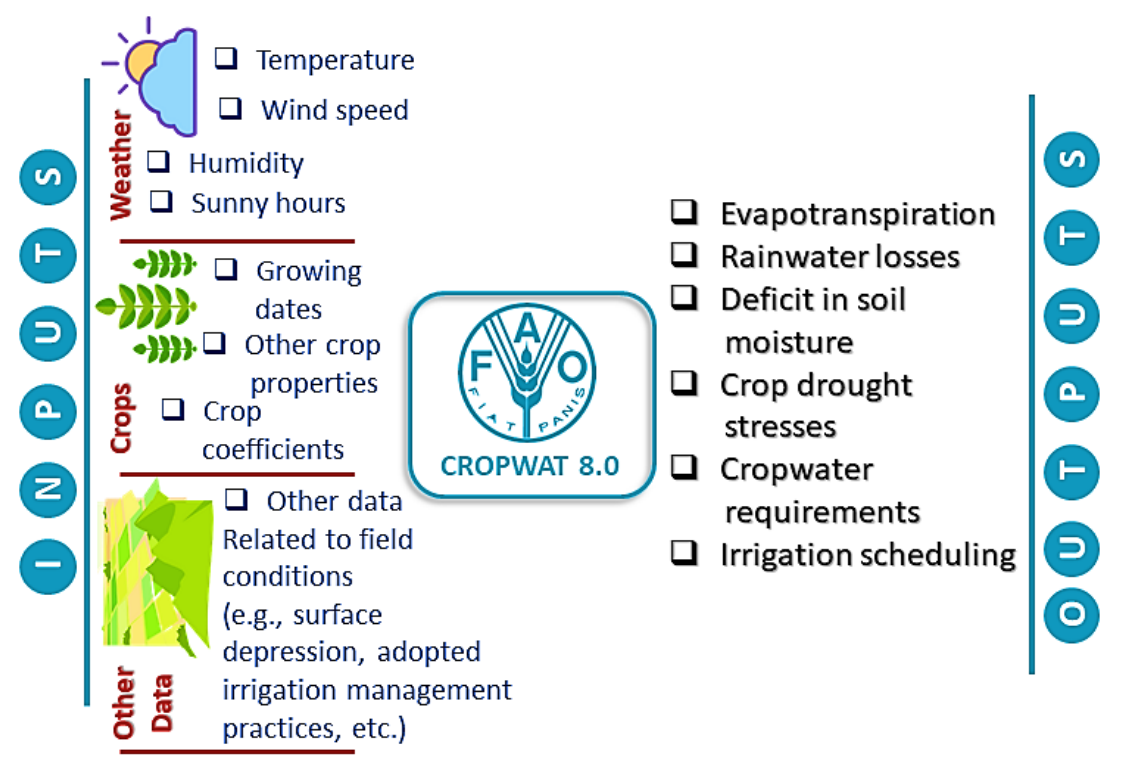

Figure 4. Main inputs and outputs of the CROPWAT model.

CROPWAT simulations for future irrigation requirements were run multiple under different values of Surface Storage Capacity to assess its role in mitigating the adverse impacts of climate change on future farmlands' water balance and irrigation requirements.

\section{Surface Storage Capacity in the CROPWAT Model}

The soil input module in the CROPWAT model comprises the input of "Maximum water depth (Figure 5)", which refers to the maximum water level over the inundated rice fields and depends on the height of field boundaries and the quality of field leveling. This item fits the definition of surface storage capacity and therefore was considered to simulate the impact of different surface storage capacities on future irrigation requirements in the study area. 


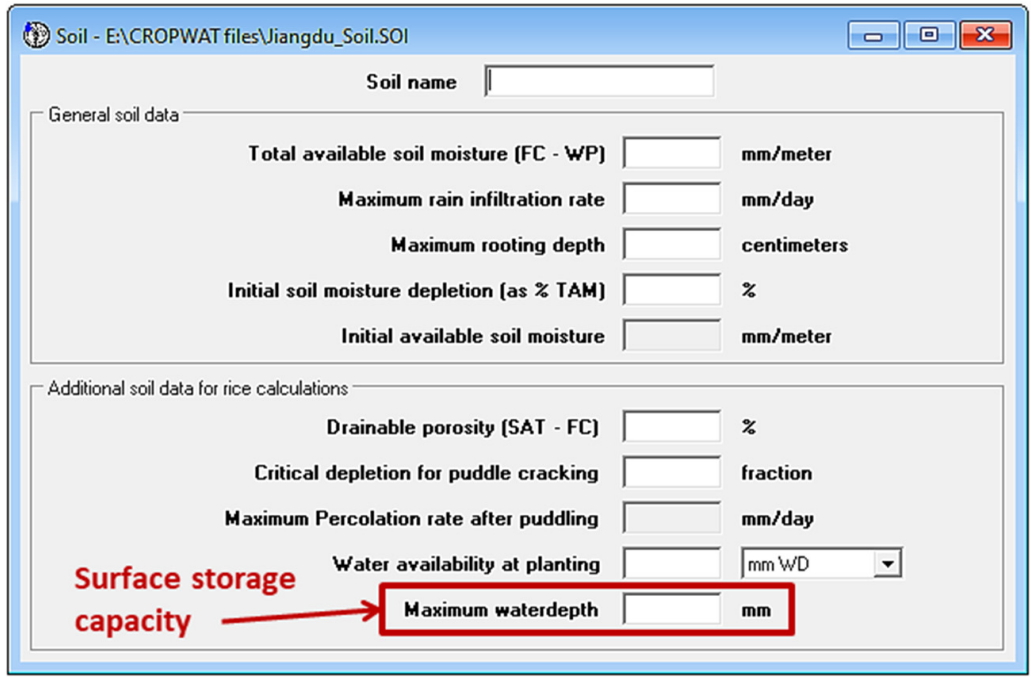

Figure 5. Soil input module in the CROPWAT model; showing the input of "Maximum water depth", which represents the Surface Storage Capacity.

Based on field observations, the surface storage capacity in the study area was about 5 $\mathrm{cm}$. Two other scenarios were considered related to the future Surface Storage Capacity in CROPWAT simulations;

- $50 \%$ higher future surface storage capacity than the current one

- $100 \%$ higher future surface storage capacity than the current one.

\subsection{Collection of Data Required to Set Up and Run the CROPWAT Model}

\subsubsection{Weather Data}

In the present study, weather data are divided into two groups;

- Baseline weather data: These data were used, alongside the other historical weather data, as a reference for comparing to future weather projections to assess the projected climate changes in the study area.

- Future weather data: These data were used as input in the CROPWAT model to estimate the future irrigation requirements of the rice-growing season in the study area.

For baseline weather data, an automated meteorological station of the type "Campbell scientific (Figure 6)" was installed in the study area to collect the daily weather data in terms of maximum and minimum temperatures, precipitation, humidity, wind speed and solar radiation, alongside many other parameters.

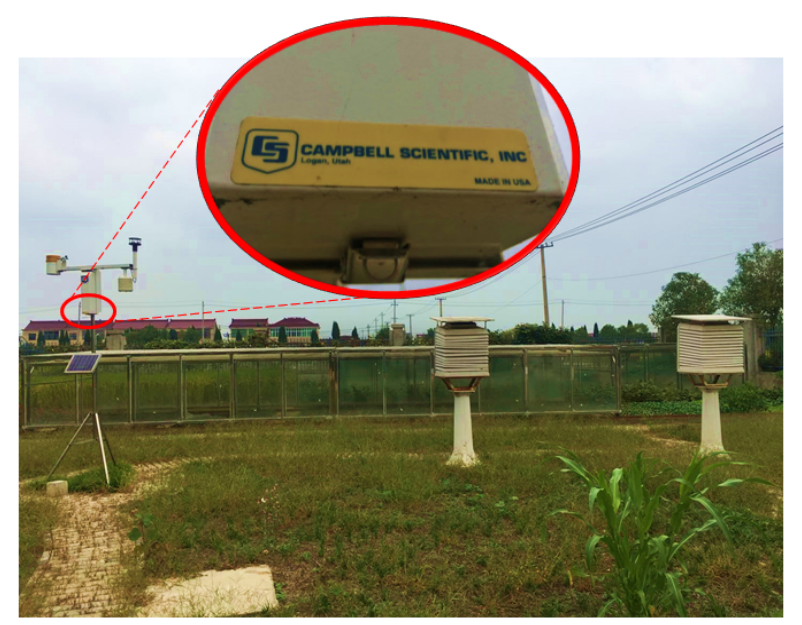

Figure 6. Setup of the meteorological station in the study area. 
For future weather data, Awad et al. [30] used the Regional Climate Downscaling Experiment (CORDEX) to project future climate changes (2021:2050) in the study area. CORDEX was established in 2013 to provide an internationally coordinated framework that improves regional climate scenarios for numerous regional domains, alongside providing new statistical methods for downscaling [31]. In the present study, we used the results reported by Awad et al. [27] to assess the future climatic changes in the study area.

\subsubsection{Soil and Crop Data}

The study area is characterized by a loamy to silt-loam soil. Table 1 lists the soil data considered in CROPWAT simulations. Crop data were determined based on FAO recommendations alongside the reported literature [32].

Table 1. Soil properties considered in CROPWAT simulations.

\begin{tabular}{cc}
\hline Soil Property & Value \\
\hline Total available soil moisture (FC-WP) & $140 \mathrm{~mm} / \mathrm{m}$ \\
Initial soil moisture depletion & $50 \%$ \\
Drainable porosity (SAT-FC) & $6 \%$ \\
Water availability at planting & $1 \mathrm{~mm} \mathrm{WD}$ \\
Maximum rain infiltration rate & $30 \mathrm{~mm} /$ day \\
\hline FC: field capacity. WP: wilting point SAT: saturation. WD: water depth.
\end{tabular}

\section{Results and Discussion}

\subsection{Future Climate Pattern in the Study Area}

\subsubsection{Daily Maximum and Minimum Temperatures}

Projections of future climate in the study area show that, under both scenarios RCP45 and RCP85, there will be remarkable increases in the daily values of maximum and minimum temperatures. Many researchers, including Gu et al. [33], have reported the same trend, stating that mostareas in the Yangtze River basin stand out as "hotspots" of climate change in China, with a high possibility of significant future increases in annual temperature. Figure 7 shows the future variation in the daily average values of maximum and minimum temperatures in the study area.

It is clear from Figure 7 that the daily values of maximum and minimum temperatures tend to be higher under RCP85, which is consistent with the reported literature, such as that in Cubasch et al. [34].

Abtew and Melesse [35] reported that global warming could directly affect evapotranspiration through many means, such as temperature increases. Thus, the projected increases in daily maximum and minimum temperatures are persumed to have a great effect on increasing the future evapotranspiration rates. Since the future highest temperature values in the study area are projected to be stationary in the months May to August, which is the rice-growing season, it is necessary to assess how such projected increases in daily temperature values will impact future evapotranspiration, and thus rice irrigation requirements. 

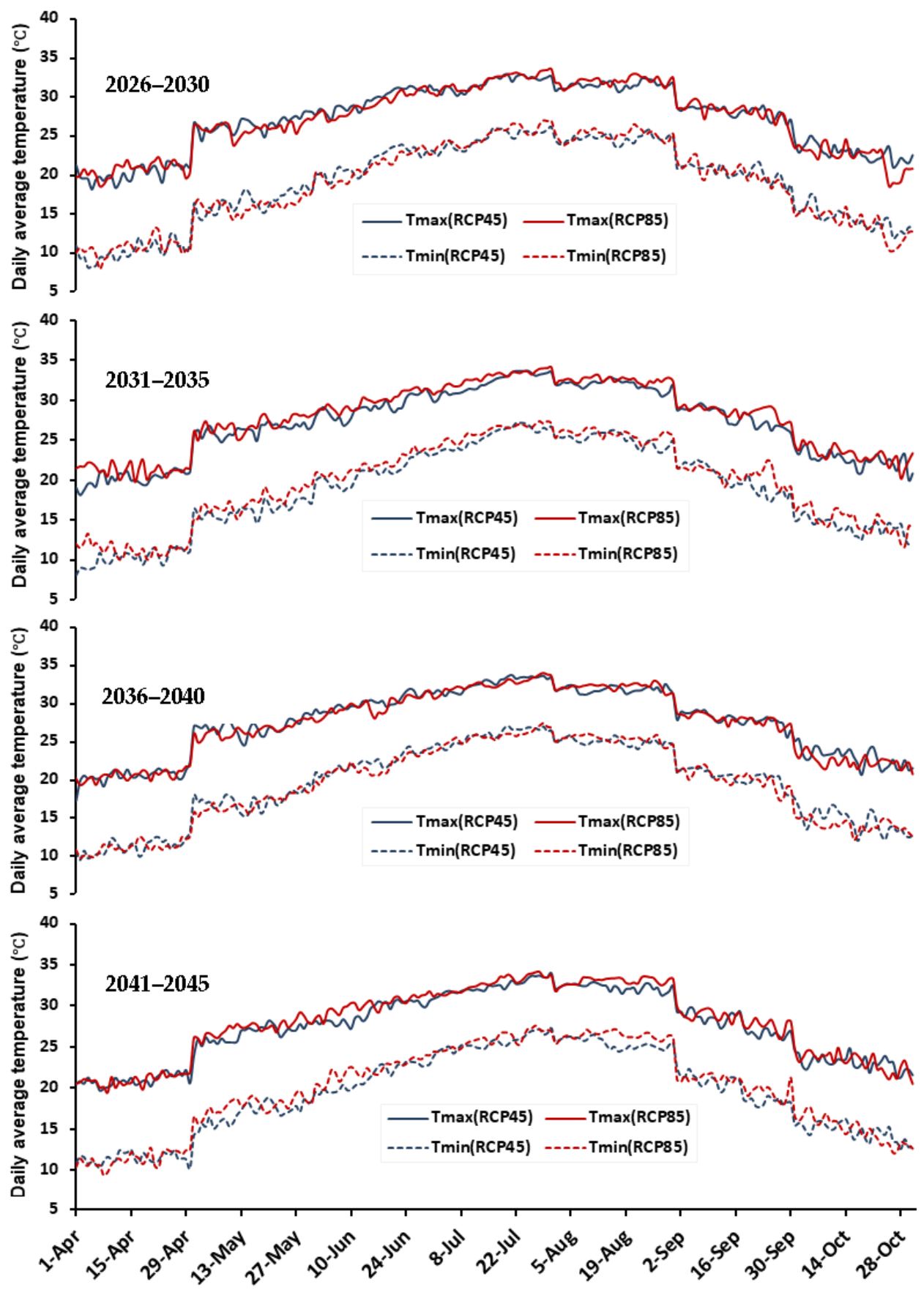

Figure 7. Future variation in daily average values of maximum and minimum temperatures in the study area, under RCP45 and RCP85.

\subsubsection{Precipitation}

Based on climate change projections, the study area will suffer from more intense precipitation events under scenarios RCP45 and RCP85. Figure 8 shows the daily contribution of rainwater as a percentage of the total seasonal rainfall. 

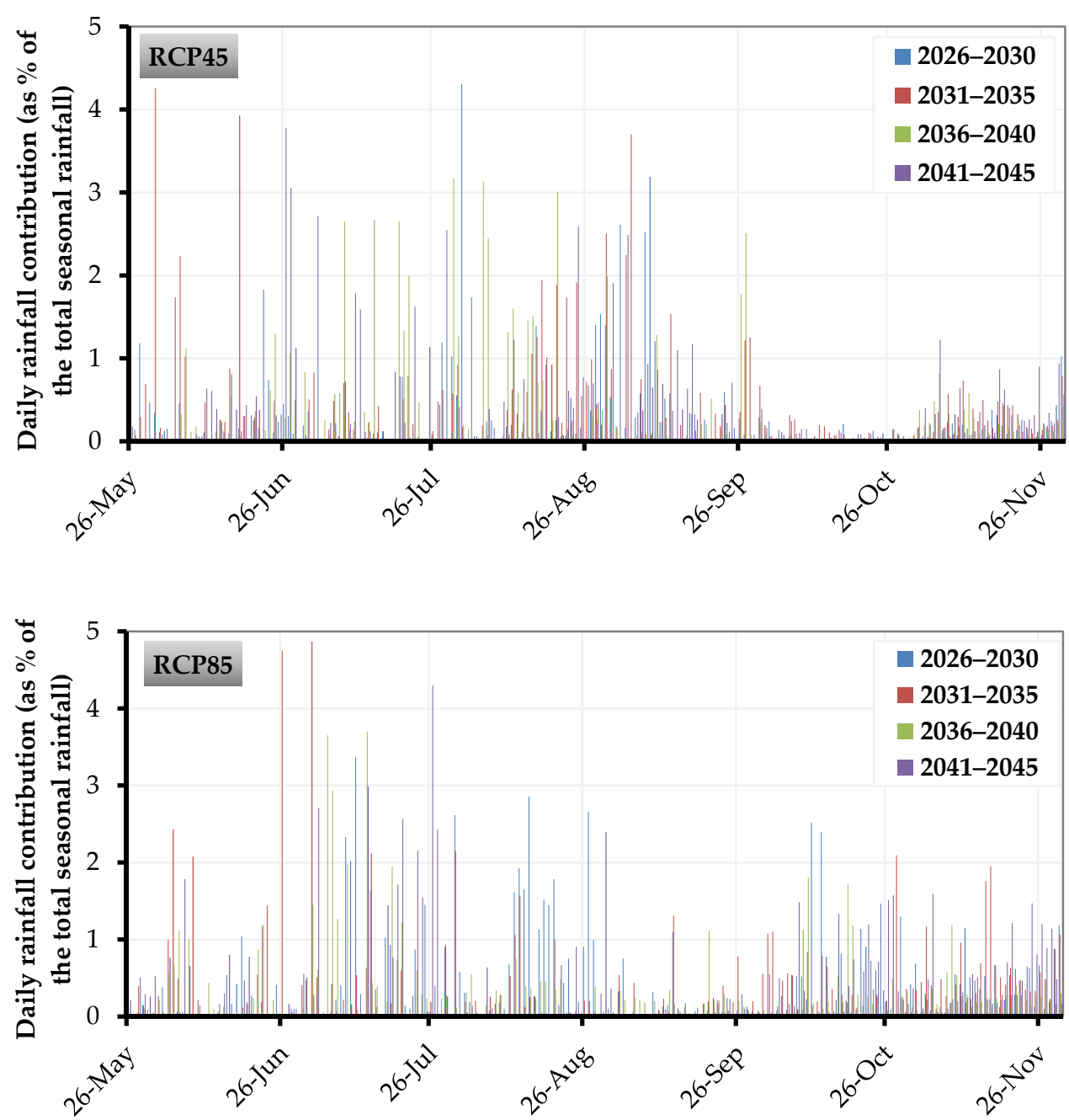

Figure 8. Daily contribution of future rainfall in the study area (as \% of the future seasonal rainfall).

\subsection{CROPWAT Simulations}

\subsubsection{CROPWAT Estimates for Future Daily Evapotranspiration}

Figure 9 shows CROPWAT estimates for the future daily evapotranspiration under RCP45 and RCP85. The figure shows that days in the months May to August are projected to have higher daily evapotranspiration values than the rest of the simulation period. This may increase the irrigation requirements on these days if there are no proper precipitation events that can provide as much soil water to compensate for these high evapotranspiration values.

\subsubsection{CROPWAT Estimates for Future Irrigation Requirements}

The CROPWAT model considers four approaches to empirically determine the rainwater losses, and thus the "effective rainfall" values that can compensate for the soil-water shortage resulting from the evapotranspiration process. In a case wherein the effective rainfall cannot entirely compensate for the soil moisture depletion, the model estimates the required irrigation that can compensate for the rest of the soil moisture depletion. This present study adopted the "USDA SCS" method to account for rainwater losses, and thus effective rainfall. 
Sustainability 2021, 13, 11802

10 of 16
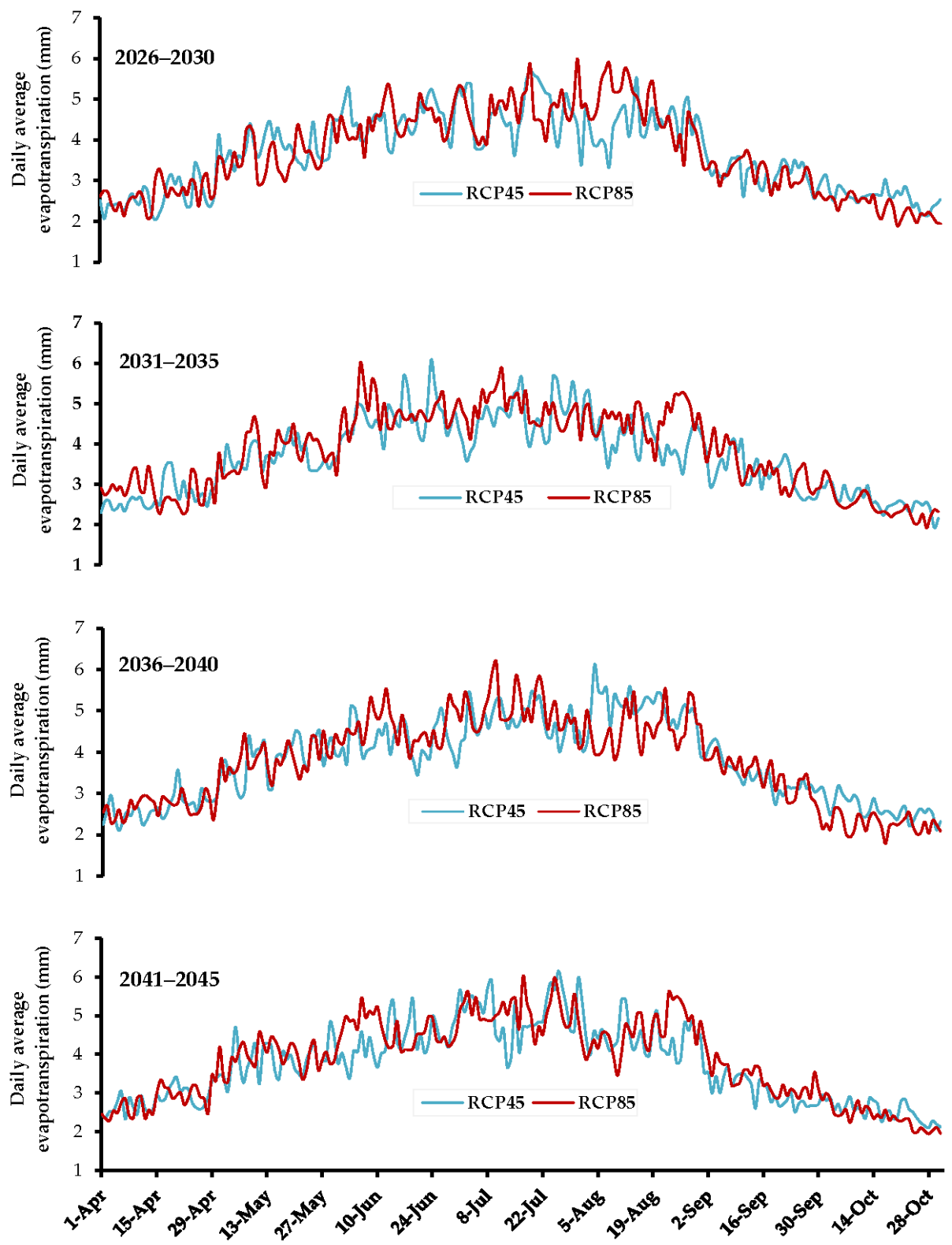

Figure 9. CROPWAT estimates for future daily evapotranspiration values in the study area, under RCP45 and RCP85.

The CROPWAT model estimates show that there will be an increase in irrigation requirements in the study area for most future periods, compared to the 2018 growing season (Figure 10). The current study's findings are consistent with the reported literature; for example, Ding et al. [36] reported that future climatic changes would increase irrigation requirements in most regions of the mid and lower reaches of the Yangtze River.

As shown in the figure, remarkable increases in future irrigation requirements are projested to occur under the RCP85 scenario. This may be due to the high evapotranspiration values, alongside the existence of many rainfall events after the end of the growing season (Figure 8), based on the here-adopted growing dates in the study area, which deprives the soil of large amounts of rainwater during the growing season. 


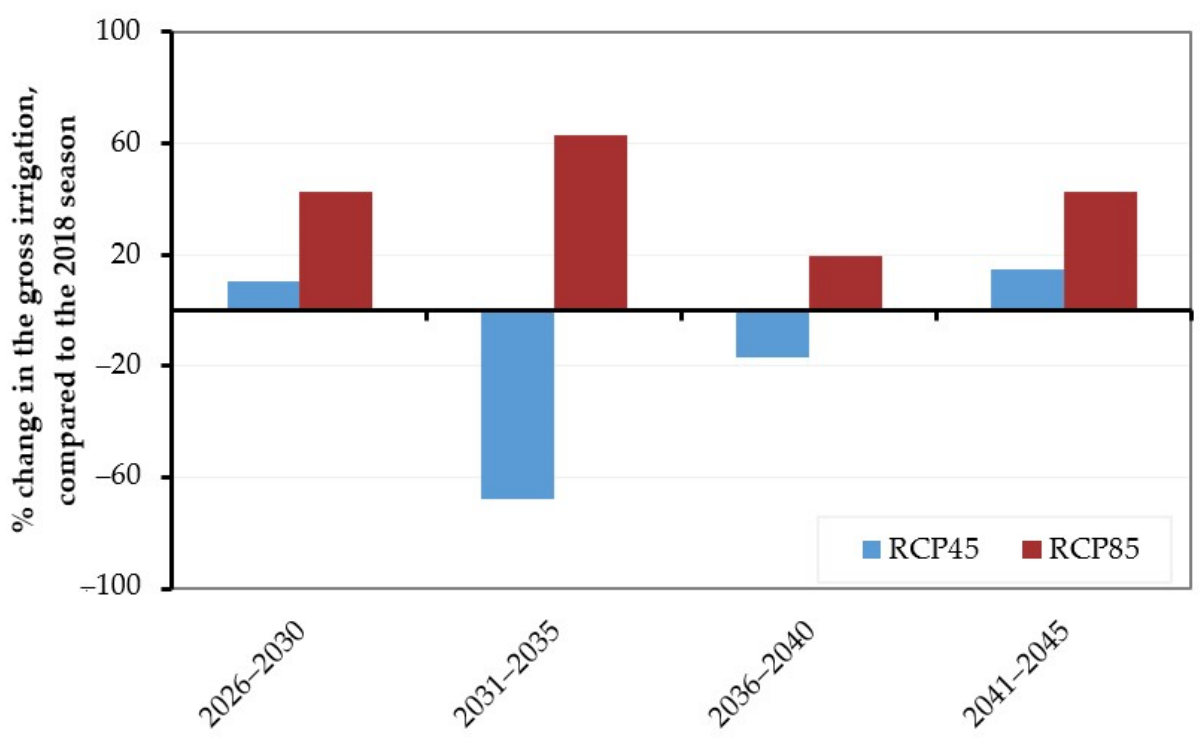

Figure 10. Future changes in irrigation requirements for the rice-growing season in the study area, under RCP45 and RCP85, compared to the 2018-2019 season, as predicted by the CROPWAT model.

3.2.3. Surface Storage Capacity: A Potential Tool to Cope with Climate Changes by Mitigating Future Rainwater Losses, Thus the Future Increase in Irrigation Requirements. CROPWAT Simulations under Different Scenarios of Surface Storage Capacities

This section aims to provide a better understanding of how to employ the Surface Storage Capacity to better utilize future rainwater, thereby mitigating the future increase in irrigation requirements caused by the projected climatic changes.

Figure 11 shows the frequency of future peak precipitation events in the study area, under RCP45, alongside the daily depletion in soil saturation as predicted by the CROPWAT model.

Furthermore, Figure 11 clarifies that rainfall events, especially the peak ones, help to increase soil moisture, and thus decrease the depletion in soil saturation, which in turn results in decreasing irrigation requirements. The rainfall pattern and future irrigation requirements have a strong relationship. As a result, many researchers have reported some techniques to most effectively utilize rainwater in order to mitigate future increases in irrigation requirements. For example, Yoon and Choi [37] found that shifting the future growing season dates to the days with more precipitation events has a great effect on decreasing future irrigation requirements, due to the better utilization of rainwater.

However, if several peak rainfall events happen consecutively and the soil is already saturated or partially saturated, there is a great possibility of losing a large portion of rainwater in the runoff if the field cannot trap the rainwater in its surface depression zones. This, in turn, will deprive the soil of this lost portion of rainwater that could (if not lost) compensate for the soil moisture depletion, and thus reduce the need for irrigation. This clarifies why it is better, regarding the irrigation requirements, to mitigate future rainwater losses through runoff. 


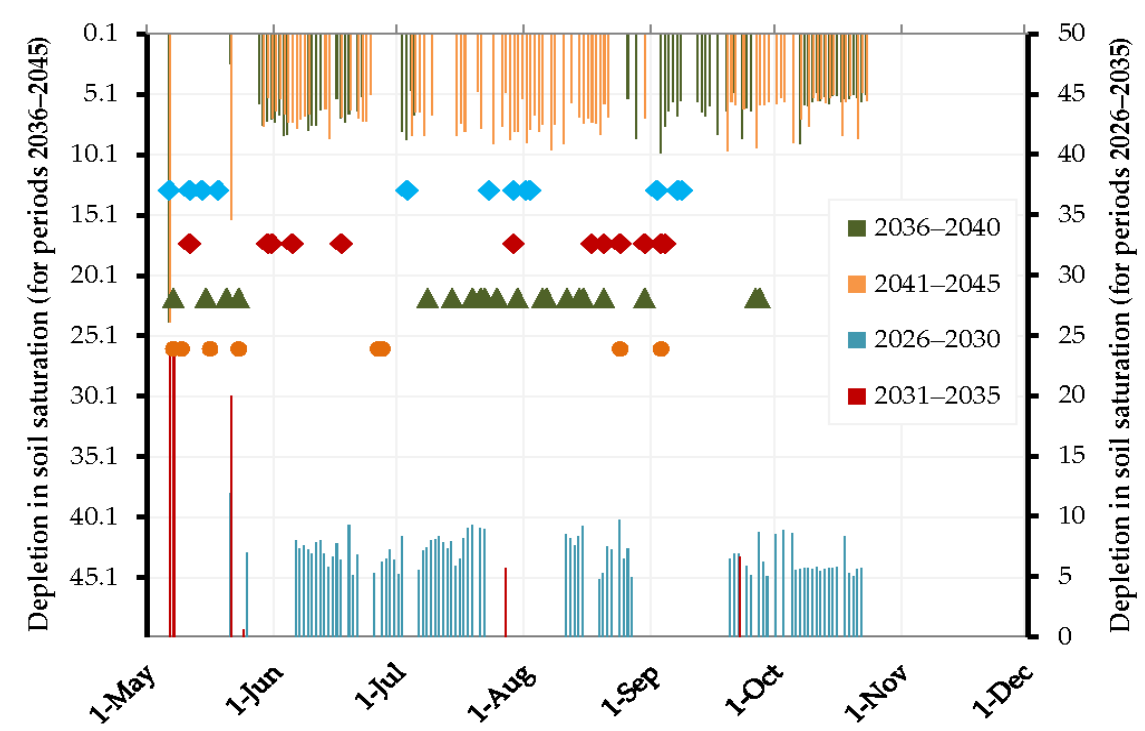

Figure 11. Future frequency of peak precipitation events in the study area under RCP45, alongside the response in soil saturation depletion to these events. Note: Bars indicate the depletion in soil moisture, while dots indicate the frequency of peak precipitation events.

Figure 12 shows CROPWAT estimates for future seasonal rainwater losses in the runoff (as \% of the total seasonal rainfall) under RCP45. To overcome and mitigate such future rainwater losses in the runoff, the CROPWAT model was rerun after increasing the Surface Storage Capacity in the study area by $50 \%$ and $100 \%$ of its baseline value $(5 \mathrm{~cm})$. In addition, Figure 12 shows that increasing the surface storage capacity will help to significantly mitigate future rainwater losses in the runoff. During some future periods, increasing the Surface Storage Capacity by $50 \%$ of its baseline value resulted in a decrease (up to more than 50\%) in future rainwater losses through runoff, compared to those at the baseline Surface Storage Capacity.

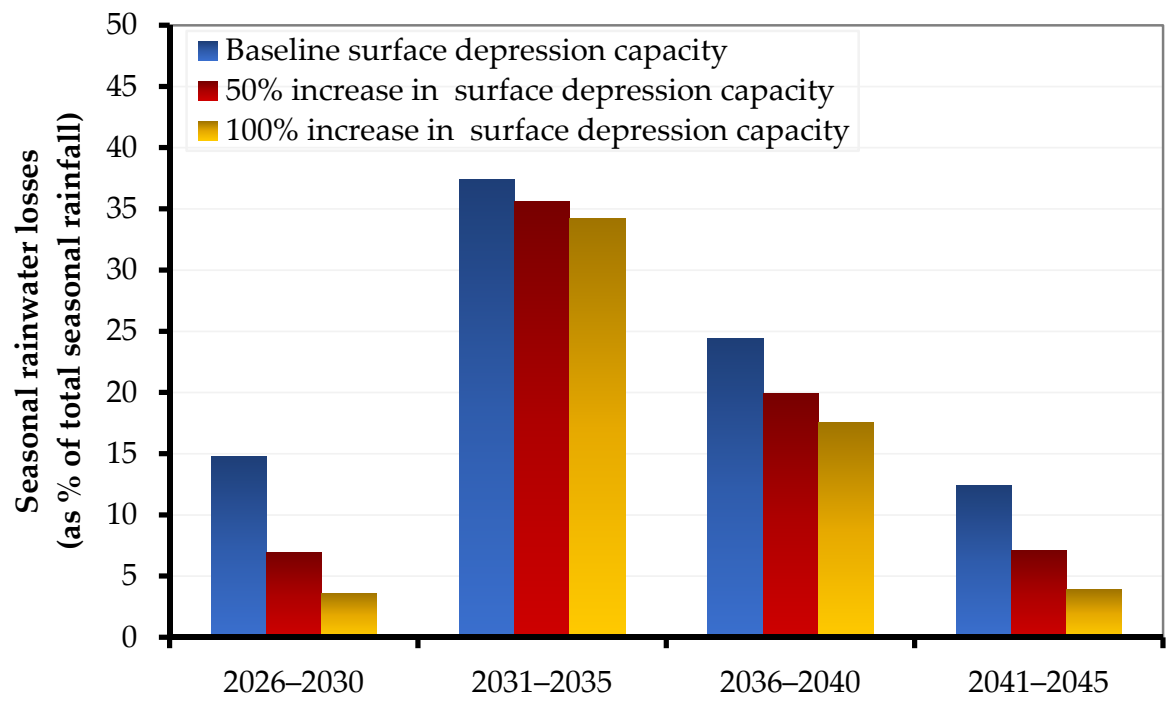

Figure 12. CROPWAT estimates for future seasonal rainwater losses, under RCP45, in the study area (as \% of the total seasonal rainfall).

The future mitigation of rainwater losses via increasing the Surface Storage Capacity is supposed to result in more available rainwater in the land. This rainwater would compensate for the depletion in soil moisture during some periods, and thus decrease the irrigation requirements. The CROPWAT simulations confirm these suppositions. Figure 13 shows the resultant saving in future irrigation requirements after increasing the Surface 
Storage Capacity. The results from the present study are consistent with several studies, such as Stern et al. [38], in which it was reported that soil surface treatments could help in decreasing runoff, thus in the better utilization of irrigation water and increasing the crop yield.

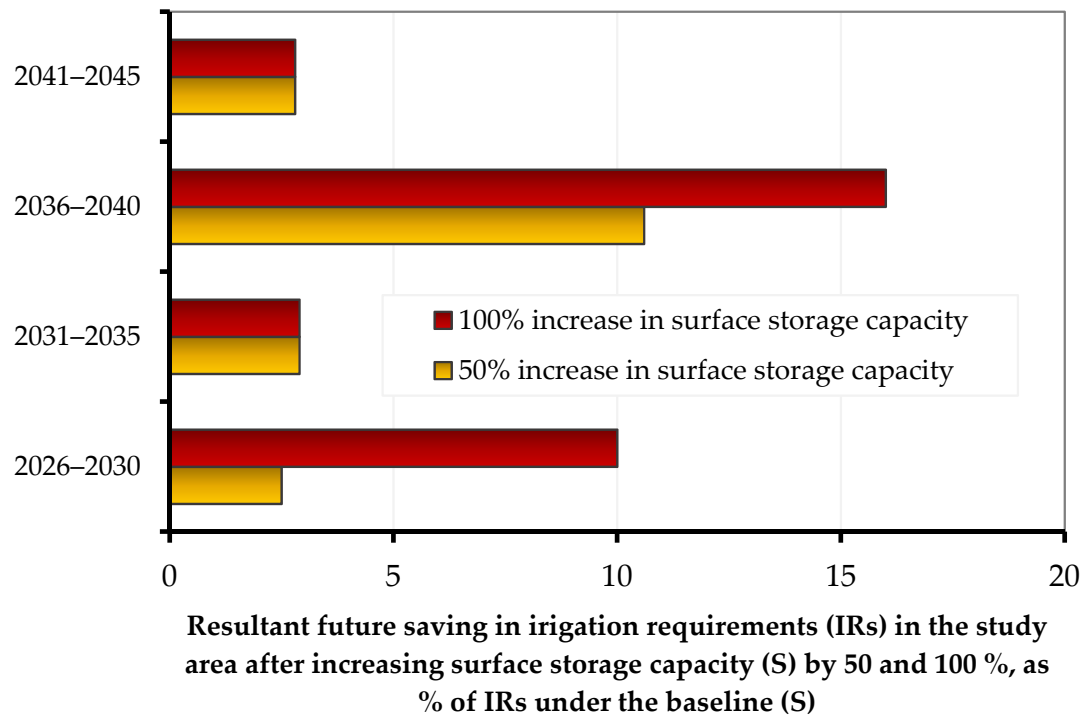

Figure 13. CROPWAT simulations for the resultant future saving in irrigation requirements (IRs) after increasing the Surface Storage Capacity under RCP45; represented as \% of IRs at the baseline Surface Storage Capacity.

The same trend was observed under RCP85, where peak precipitation events contributed much in compensating for the soil moisture deficit (Figure 14). Additionally, increasing the surface storage capacity under RCP85 significantly mitigated future rainwater losses in the study area (Figure 15). During some future periods, the increase in surface storage capacity will result in "ZERO" future rainwater losses in the runoff, reflecting the best utilization of rainwater, thus decreasing future irrigation requirements.

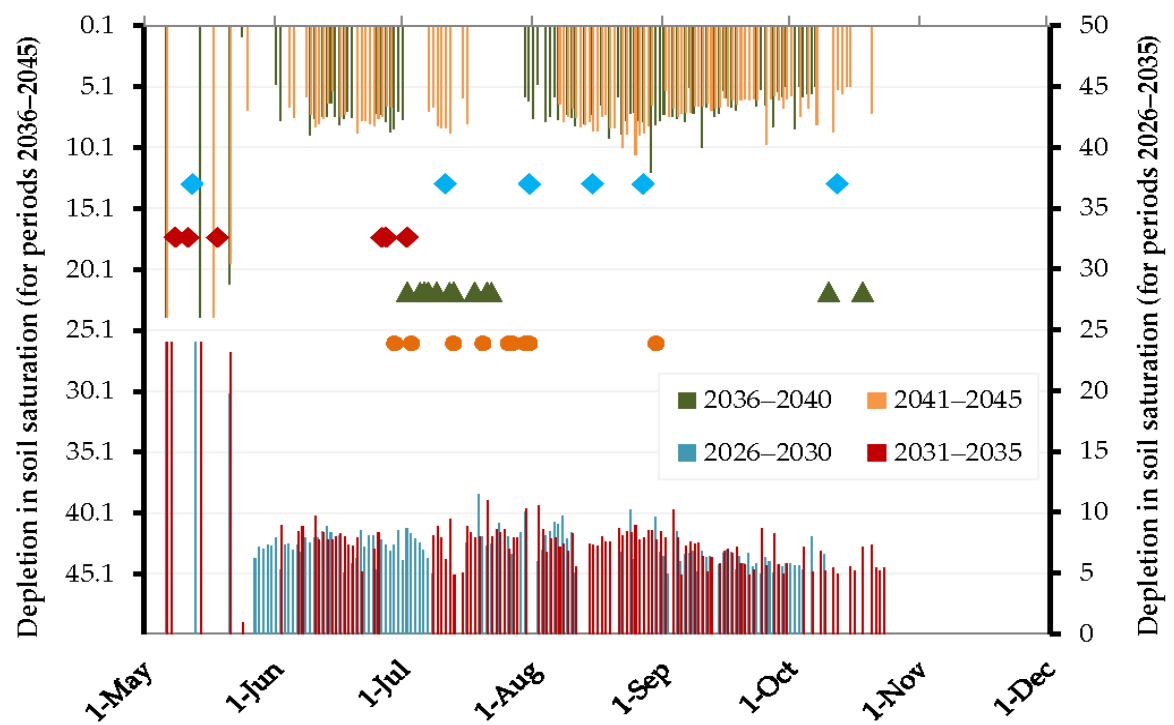

Figure 14. Future frequency of peak precipitation events in the study area under RCP85, alongside the response in soil saturation depletion to these events. Note: Bars indicate the depletion in soil moisture, while dots indicate the frequency of peak precipitation events. 


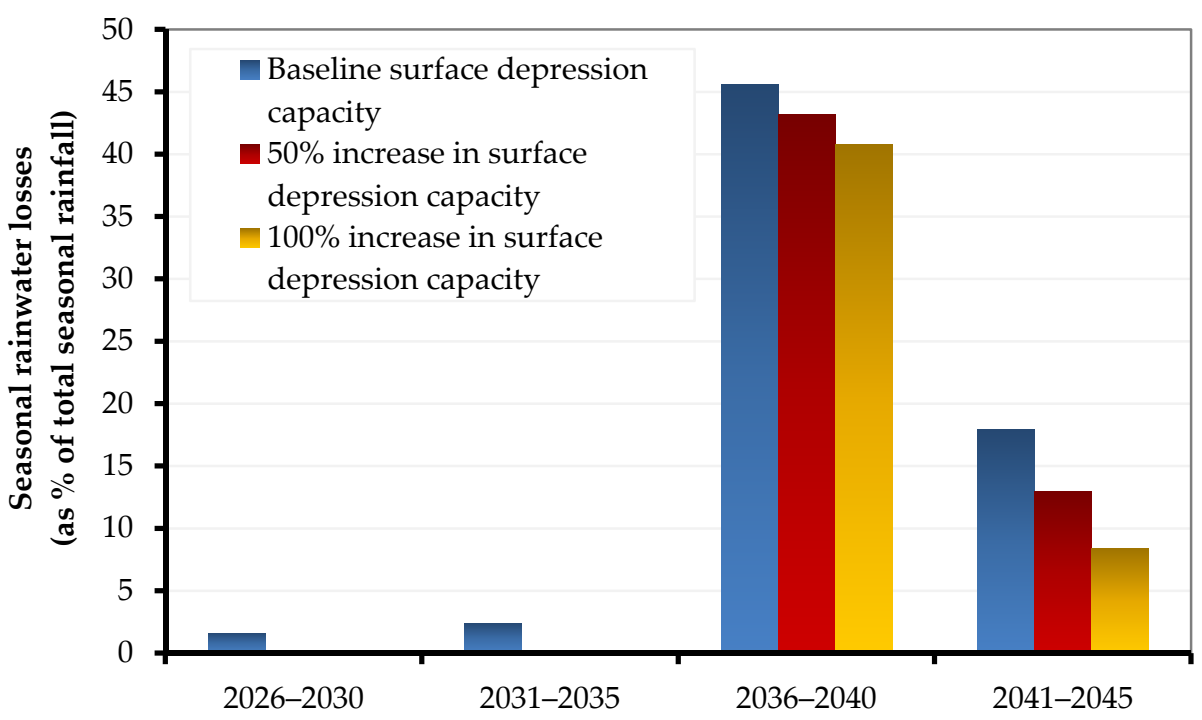

Figure 15. CROPWAT estimates for future seasonal rainwater losses, under RCP85, in the study area (as $\%$ of the total seasonal rainfall).

\section{Conclusions}

The projected climatic changes at the lower reaches of the Yangtze River basin will increase future irrigation requirements (by up to $15 \%$ and $65 \%$, compared to the 2018 season, under RCP45 and RCP85, respectively), with the possibility of threatening the quality of adjacent water bodies due to the rainwater runoff from these lands. The present study aims to assess whether farmers can self-adapt their farmlands to climate changes through simple practices, thereby mitigating climate change's adverse impacts on these farmlands while also protecting the quality of adjacent water bodies.

CROPWAT simulations show that increasing Surface Storage Capacity (SSC) (by 50\% and $100 \%$ of its baseline value), which is a simple act for farmers in the study area, will reduce future rainwater runoff by up to $76 \%$ and $100 \%$ (for a $50 \%$ increase in SSC) and $53 \%$ and $100 \%$ (for a $100 \%$ increase in SSC) under RCP45 and RCP 85 , respectively. CROPWAT simulations also revealed that the resultant mitigation in future rainwater runoff will mitigate the future increase in irrigation requirements; e.g., up to about $11 \%$ and $16 \%$ of future irrigation requirements will be saved under RCP45 when increasing the SSC by 50\% and $100 \%$ of its baseline value, respectively.

Therefore, educating farmers on how to adjust the level of their farmland's boundaries according to the weather forecast can significantly help to mitigate future rainwater runoff, thus decreasing irrigation requirements and preserving the quality of adjacent water bodies.

The present study's results confirm the potential role of increasing farmers' awareness, an underutilized approach, in reducing the aggravation of climate change's adverse impacts in farmlands and the surrounding environment, thus also easing adaptation policies.

Author Contributions: Methodology, W.L. and A.A.; software, A.A. and M.E.-S.G.; supervision, W.L.; writing-original draft, A.A.; writing—review and editing, W.L., M.E.-R., N.A.-A., A.E. and H.N.F. All authors have read and agreed to the published version of the manuscript.

Funding: This research received no external funding.

Institutional Review Board Statement: Not applicable.

Informed Consent Statement: Not applicable.

Data Availability Statement: Not applicable. 
Acknowledgments: The authors would like to express their sincere appreciation to all of Luo's lab members, College of Water Resources and Hydropower Engineering, Yangzhou University, for their continuous help. Thanks extend to the anonymous reviewers for their valuable comments and suggestions.

Conflicts of Interest: The authors declare no conflict of interest.

\section{References}

1. Masson-Delmotte, V.; Zhai, P.; Pirani, A.; Connors, S.L.; Péan, C.; Berger, S.; Caud, N.; Chen, Y.; Goldfarb, L.; Gomis, M.I.; et al. Climate Change 2021: The Physical Science Basis; Contribution of Working Group I to the Sixth Assessment Report of the Intergovernmental Panel on Climate Change; Cambridge University Press: Cambridge, UK, 2021.

2. Vahid, K.; Karami, E.; Keshavarz, M. Climate Change and Agriculture: Impacts and Adaptive Responses in Iran. J. Integr. Agric. 2018, 17, 1-15.

3. Chandio, A.A.; Jiang, Y.; Rehman, A.; Rauf, A. Short and Long-Run Impacts of Climate Change on Agriculture: An Empirical Evidence from China. Int. J. Clim. Chang. Strateg. Manag. 2020, 12, 201-221. [CrossRef]

4. Singh, M.G.; Kaur, M.; Kaushik, P. Impact of Climate Change on Agriculture and Its Mitigation Strategies: A Review. Sustainability 2021, 13, 1318.

5. Buda, S.; Gemmer, M.; Jiang, T. Spatial and Temporal Variation of Extreme Precipitation over the Yangtze River Basin. Quat. Int. 2008, 186, 22-31.

6. Jiabo, Y.; Gentine, P.; Zhou, S.; Sullivan, S.C.; Wang, R.; Zhang, Y.; Guo, S. Large Increase in Global Storm Runoff Extremes Driven by Climate and Anthropogenic Changes. Nat. Commun. 2018, 9, 4389.

7. Clausius, R. Ueber Die Bewegende Kraft Der Wärme Und Die Gesetze, Welche Sich Daraus Für Die Wärmelehre Selbst Ableiten Lassen. Ann. Phys. 1850, 155, 368-397. [CrossRef]

8. Xiao, W.; Hao, F.; Cheng, H.; Yang, S.; Zhang, X.; Bu, Q. Estimating Non-Point Source Pollutant Loads for the Large-Scale Basin of the Yangtze River in China. Environ. Earth Sci. 2011, 63, 1079-1092.

9. Yufu, Z.; Wu, H.; Yao, M.; Zhou, J.; Wu, K.; Hu, M.; Shen, H.; Chen, D. Estimation of Nitrogen Runoff Loss from Croplands in the Yangtze River Basin: A Meta-Analysis. Environ. Pollut. 2021, 272, 116001.

10. Ai, W.; Yang, D.; Tang, L. Spatiotemporal Variation in Nitrogen Loads and Their Impacts on River Water Quality in the Upper Yangtze River Basin. J. Hydrol. 2020, 590, 125487.

11. Whitehead, P.G.; Wilby, R.L.; Battarbee, R.W.; Kernan, M.; Wade, A.J. A Review of the Potential Impacts of Climate Change on Surface Water Quality. Hydrol. Sci. J. 2009, 54, 101-123. [CrossRef]

12. Yuan, T.; Liu, J.; Guan, X.; Chen, H.; Ren, X.; Wang, S.; Ji, M. Estimation of Potential Agricultural Non-Point Source Pollution for Baiyangdian Basin, China, under Different Environment Protection Policies. PLoS ONE 2020, 15, e0239006.

13. Jabbar, F.K.; Grote, K. Statistical Assessment of Nonpoint Source Pollution in Agricultural Watersheds in the Lower Grand River Watershed, MO, USA. Environ. Sci. Pollut. Res. 2019, 26, 1487-1506. [CrossRef]

14. Yan, L.; Li, H.; Cui, G.; Cao, Y. Water Quality Attribution and Simulation of Non-Point Source Pollution Load Flux in the Hulan River Basin. Sci. Rep. 2020, 10, 3012.

15. Gordon, A.J.; Morton, L.W.; Hobbs, J. Farmer Beliefs and Concerns about Climate Change and Attitudes toward Adaptation and Mitigation: Evidence from Iowa. Clim. Chang. 2013, 118, 551-563.

16. Hillel, D. Soil-Water Cycle; Academic Press: Cambridge, MA, USA, 2008; pp. 103-120.

17. Ritesh, K.; Tagert, M.L.M.; Paz, J.O. Evaluating the Nutrient Reduction and Water Supply Benefits of an on-Farm Water Storage (Ofws) System in East Mississippi. Agric. Ecosyst. Environ. 2018, 265, 476-487.

18. Ngigi, S.N.; Savenije, H.H.G.; Thome, J.N.; Rockström, J.; de Vries, F.W.T.P. Agro-Hydrological Evaluation of on-Farm Rainwater Storage Systems for Supplemental Irrigation in Laikipia District, Kenya. Agric. Water Manag. 2005, 73, 21-41. [CrossRef]

19. Gunasekhar, N.; Halpin, N.V.; Bell, M.J. Impact of Practice Change on Runoff Water Quality and Vegetable Yield-An on-Farm Case Study. Agriculture 2017, 7, 30.

20. Martin, S. CROPWAT: A Computer Program for Irrigation Planning and Management; Food and Agriculture Organization of the United Nations: Rome, Italy, 1992.

21. Elsayed, G.M.; Fattouh, E.M. Assessment of Irrigation Management Practices Using FAO-CROPWAT 8, Case Studies: Tina Plain and East South El-Kantara, Sinai, Egypt. Ain Shams Eng. J. 2021, 12, 1623-1636.

22. Branislava, L.; Francia, M.; Jacimovic, G. Assessment of Climate Change Impact on Crop Water Requirements in Serbia in 2030 Using CROPWAT Model. In Proceedings of the International Scientific Conference on Environmental Changes and Adaptation Strategies, Skalica, Slovakia, 9-11 September 2013.

23. Ahmad, B.S.; Pandit, B.A.; Khan, J.N.; Kumar, R.; Jan, R. Water Requirements and Irrigation Scheduling of Maize Crop Using CROPWAT Model. Int. J. Curr. Microbiol. Appl. Sci. 2017, 6, 1662-1670.

24. Jia, Z.; Chen, C.; Luo, W.; Zou, J.; Wu, W.; Xu, M.; Tang, Y. Hydraulic Conditions Affect Pollutant Removal Efficiency in Distributed Ditches and Ponds in Agricultural Landscapes. Sci. Total. Environ. 2019, 649, 712-721. [CrossRef] [PubMed]

25. Javad, G.; Gholizadeh, B. Prediction of Rice Water Requirement Using FAO-CROPWAT Model in North Iran under Future Climate Change. Preprints 2016, 2016100134. Available online: https:/ /www.preprints.org/manuscript/201610.0134/v1 (accessed on 20 October 2021). 
26. Memon, A.V.; Jamsa, S. Crop Water Requirement and Irrigation Scheduling of Soybean and Tomato Crop Using CROPWAT 8.0. Int. Res. J. Eng. Technol. 2018, 5, 669-671.

27. Doria, R.; Madramootoo, C.A.; Mehdi, B.B. Estimation of Future Crop Water Requirements for 2020 and 2050, Using CROPWAT. In Proceedings of the 2006 IEEE EIC Climate Change Conference, Ottawa, ON, Canada, 10-12 May 2006.

28. Saon, B.; Chatterjee, S.; Sarkar, S.; Jena, S. Projecting Future Crop Evapotranspiration and Irrigation Requirement of Potato in Lower Gangetic Plains of India Using the CROPWAT 8.0 Model. Potato Res. 2016, 59, 313-327.

29. Akshay, S.; Deepthi, B.; Mirajkar, A.B.; Adarsh, S. Modeling Future Irrigation Water Demands in the Context of Climate Change: A Case Study of Jayakwadi Command Area, India. Model. Earth Syst. Environ. 2021, 7, 1963-1977.

30. Ahmed, A.; Luo, W.; Zou, J. DRAINMOD Simulation of Paddy Field Drainage Strategies and Adaptation to Future Climate Change in Lower Reaches of the Yangtze River Basin. Irrig. Drain. 2021, 70, 819-831.

31. Daniela, J.; Elizalde, A.; Haensler, A.; Hagemann, S.; Kumar, P.; Podzun, R.; Rechid, D.; Remedio, A.R.; Saeed, F.; Sieck, K. Assessing the Transferability of the Regional Climate Model Remo to Different Coordinated Regional Climate Downscaling Experiment (Cordex) Regions. Atmosphere 2012, 3, 181-199.

32. Yong, L.; Yang, X.; Ye, Q.; Huang, W. Variation Characteristics of Rice Water Requirement in Middle and Lower Reaches of Yangtze River during 19612007. Trans. Chin. Soc. Agric. Eng. 2011, 27, 175-183.

33. Huanghe, G.; Yu, Z.; Wang, G.; Wang, J.; Ju, Q.; Yang, C.; Fan, C. Impact of Climate Change on Hydrological Extremes in the Yangtze River Basin, China. Stoch. Environ. Res. Risk Assess. 2015, 29, 693-707.

34. Ulrich, C.; Meehl, G.A.; Boer, G.J.; Stouffer, R.J.; Dix, M.; Noda, A.; Senior, C.A.; Raper, S.; Yap, K.S. Projections of Future Climate Change. In Climate Change 2001: The Scientific Basis; Contribution of Wg1 to the Third Assessment Report of the Ipcc (Tar); Cambridge University Press: Cambridge, UK, 2001; pp. 525-582.

35. Wossenu, A.; Melesse, A. Climate Change and Evapotranspiration. In Evaporation and Evapotranspiration; Springer: Berlin/Heidelberg, Germany, 2013; pp. 197-202.

36. Yimin, D.; Wang, W.; Song, R.; Shao, Q.; Jiao, X.; Xing, W. Modeling Spatial and Temporal Variability of the Impact of Climate Change on Rice Irrigation Water Requirements in the Middle and Lower Reaches of the Yangtze River, China. Agric. Water Manag. 2017, 193, 89-101.

37. Reun, Y.P.; Choi, J. Effects of Shift in Growing Season Due to Climate Change on Rice Yield and Crop Water Requirements. Paddy Water Environ. 2020, 18, 291-307.

38. Stern, R.; van der Merwe, A.J.; Laker, M.C.; Shainberg, I. Effect of Soil Surface Treatments on Runoff and Wheat Yields under Irrigation. Agron. J. 1992, 84, 114-119. [CrossRef] 